\title{
Estrategias de adaptación al medio, de dos comunidades indígenas (Butku y Awastingni) después del huracán Félix en el Caribe Nicaragüense
}

\author{
Juan Carlos Ocampo \\ Universidad Centroamericana (UCA)
}

Buenas tardes a todos. En principio quiero agradecer mi presencia a don Albert Sinclair. Esta es una investigación que hice entre septiembre de 2008 y febrero de 2009. La finalidad principal era poder elaborar un trabajo final para poder optar al título de ingeniero en Sistemas de Producción Agropecuaria, en la Universidad Centroamericana. Está centrada en el comunitario; no es un análisis técnico de algún sistema productivos; no analiza ninguna intervención, lo que hace es sistematizar las estrategias de las familias después del huracán: qué es lo que han intentado hacer para poder sobrevivir. Una cosa importante es que la rehabilitación después del huracán tiene distintos rostros (social, económico, ambiental), esta investigación intenta abordar el más importante: la estrategia de las comunidades en su rehabilitación. Esperamos con esto contribuir al debate y comprensión de lo que pasó en las comunidades luego del huracán Félix y así poder actuar y mejorar las respuestas que puedan dar las comunidades en futuras perturbaciones de este tipo.

Para los líderes comunitarios, este fenómeno fue algo nunca antes visto. Sin embargo evidencia el nivel de importancia de los medios de vida en las estrategias de familias.

\section{Objetivos de la investigación}

\section{General}

Entender las estrategias de adaptación al medio de las comunidades indígenas de Butku y Awastingni, después del huracán Félix en el Caribe nicaragüense.

\section{Específicos}

- Caracterizar las estrategias de vida de las comunidades de Butku y Awastingni
- Analizar los factores determinantes en las estrategias de adaptación en las comunidades de estudio. Qué es lo que han hecho y por qué lo han hecho.

- Proponer acciones de desarrollo basadas en las condiciones del entorno actual.

No podemos hablar de las estrategias de adaptación si no caracterizamos primero las estrategias de vida que llevaban antes del Huracán.

\section{Hipótesis}

- La afectación de los medios de vida modifica sustancialmente las estrategias de vida.

- Los comunitarios optan por medidas de intensificación de sus sistemas productivos como estrategia de adaptación.

\section{Marco Teórico}

Nos basamos en los siguientes conceptos que utiliza la FAO.

- Medios de vida: posibilidades, activos y actividades que permiten ganarse la vida.

- Estrategia de vida: actividad que ha dado resultado en ausencia de crisis

- Estrategia de adaptación: actividad experimental en condiciones de crisis.

- Estructuralmente hablamos de medios de vida, pero funcionalmente hablamos de estrategias de vida o de adaptación campesina, indígena. 
- Relación Estrategias de vida vs Estrategias de Adaptación, lo que da un sistema de vida

Preguntas de investigación

- ¿Cuáles eran los medios de vida antes del huracán?

- ¿Cuáles eran las estrategias de vida y cuál era su naturaleza?

- ¿Cuáles son las estrategias de adaptación?
- ¿Cuáles son los medios que las sustentan?

\section{Metodología}

Tipo de estudio: exploratorio-cualitativo. Es exploratorio puesto que no existen todavía estudios a profundidad sobre cómo un grupo humano racionaliza lo que le ha pasado para poder adaptarse.

\section{Resultados de la investigación}

Presento una tabla que sintetiza lo que son los medios de vida.

\begin{tabular}{|c|c|c|}
\hline Activo/actividad agregado & Activos & Actividades \\
\hline \multirow[t]{4}{*}{ Bosque } & FAUNA & CAZA \\
\hline & RECURSO FORESTAL & APROVECHAMIENTO FORESTAL \\
\hline & Productos no forestales & Aprovechamiento de productos no forestales \\
\hline & $\begin{array}{l}\text { Fundamento de aspectos de } \\
\text { la cosmogonía local. }\end{array}$ & $\begin{array}{l}\text { Herencia y recreación de la cosmogonía local: } \\
\text { mitos, personajes, leyendas, creencias, etc. }\end{array}$ \\
\hline \multirow[t]{6}{*}{ Ríos y afluentes } & PECES & PESCA \\
\hline & Disponibilidad de agua & Aseo personal, lavandería, consumo. \\
\hline & $\begin{array}{l}\text { Fundamento de aspectos de } \\
\text { la cosmogonía }\end{array}$ & $\begin{array}{l}\text { Herencia y recreación de la cosmogonía local: } \\
\text { mitos, personajes, leyendas, creencias, etc. }\end{array}$ \\
\hline & RED DE DRENAJE & TRANSPORTE \\
\hline & $\begin{array}{l}\text { Fuente de productos exóticos } \\
\text { de comercialización }\end{array}$ & $\begin{array}{l}\text { Caza y comercialización de pieles de lagarto, } \\
\text { de perro de agua. }\end{array}$ \\
\hline & $\begin{array}{l}\text { Espacio para cultivo en las } \\
\text { riberas de ríos y afluentes. }\end{array}$ & Cultivo de frijol y de maíz. \\
\hline \multirow[t]{3}{*}{ AGRICULTURA } & $\begin{array}{l}\text { Variabilidad genética de } \\
\text { distintos cultivos }\end{array}$ & Agricultura en dos o tres periodos en el año. \\
\hline & $\begin{array}{l}\text { Variabilidad genética de } \\
\text { distintos frutales }\end{array}$ & Establecimiento de frutales. \\
\hline & $\begin{array}{l}\text { Material vegetativo de } \\
\text { hortalizas }\end{array}$ & Cultivo de hortalizas \\
\hline
\end{tabular}




\begin{tabular}{|l|l|l|}
\hline COMERCIALIZACIÓN & $\begin{array}{l}\text { Distintos productos } \\
\text { agrícolas }\end{array}$ & Venta de productos agrícolas \\
\hline & $\begin{array}{l}\text { Distintos productos no } \\
\text { agrícolas }\end{array}$ & Venta de productos no agrícolas \\
\hline
\end{tabular}

\begin{tabular}{|c|c|c|}
\hline El patio & Disponibilidad de espacio & Construcción de viviendas \\
\hline & & Manejo de frutales \\
\hline & & Manejo de plantas medicinales y especias. \\
\hline & & Manejo de especies menores \\
\hline & & Manejo de especies mayores \\
\hline \multirow[t]{6}{*}{ El llano } & Fauna & La caza \\
\hline & Especies forestales & Aprovechamiento forestal \\
\hline & Espacio para cultivo & Actividades agrícolas \\
\hline & $\begin{array}{l}\text { Quebradas cercanas a la } \\
\text { comunidad }\end{array}$ & $\begin{array}{l}\text { Aseo personal, lavandería, extracción de } \\
\text { agua para consumo. }\end{array}$ \\
\hline & Árboles frutales silvestres & Recolección de nancite y guayaba silvestres \\
\hline & Extensiones de llano & Pastoreo extensivo de ganado bovino \\
\hline \multirow[t]{4}{*}{ Activo social } & Mano vuelta o mihta alki & Contratar mano de obra \\
\hline & Klahka mana & Compartir productos diversos \\
\hline & La organización comunitaria & Trabajo por granos básicos \\
\hline & La familia & Trabajo por implementos agrícolas \\
\hline \multirow[t]{4}{*}{ Activo material } & Implementos agrícolas & \\
\hline & $\begin{array}{l}\text { Equipos importantes: rifle } \\
\text { 22, motosierra, motor fuera } \\
\text { de borda. }\end{array}$ & \\
\hline & $\begin{array}{l}\text { Medios de transporte: } \\
\text { canoa, caballo }\end{array}$ & \\
\hline & $\begin{array}{l}\text { Habilidad para construir } \\
\text { canoas o manejar una } \\
\text { motosierra. }\end{array}$ & \\
\hline
\end{tabular}




\section{El recurso forestal como medio de vida generador de ingresos monetarios}

- En Awastigni se ha pasado de lógica de extracción a lógica de manejo sustentable.

- YAMABA empleaba a febrero de 2009 a un $45 \%$ de la población; un 40 \% lo hacía a título personal. Un 60 \% espera trabajar en la empresa a mediano y largo plazo.

- Butku (SIPBAA): el huracán Félix derribó el área de PGM, ha tenido serias deficultades para aprovechar y comercializar; se intensifican las actividades de reforestación y la diversificación de rubros.

- El SIPBAA empleó al $40 \%$ de la población de Butku entre enero y septiembre de 2008, un $30 \%$ lo hacía a título personal.

- El debate: ¿estas iniciativas nacen de la comunidad o son una importación? ¿Qué tanto nivel de apropiación existe? ¿Qué nivel de impacto generan a nivel social, económico y ambiental? ¿Que lecciones aprendidas existen?

\section{La construcción de viviendas: una necesidad evidente.}

El 90 \% de la población que ha construido sus viviendas. Muchos aún no tienen vivienda, aún cuando fueron apoyados.

El lento proceso de reconstrucción de viviendas evidencia: el alto nivel de vulnerabilidad, inadecuada organización, priorización de la necesidades familiares; falta de adaptación de la manera tradicional de construir viviendas.

\section{Conclusiones}

- El huracán Félix modificó sustancialmente los medios de vida; y se han modificado las estrategias de vida en el corto y mediano plazo.

- Los comunitarios recomponen sus estrategias de vida mediante actividades que buscan satisfacer sus necesidades básicas.

- Como estrategia: recibir ayuda externa en alimento; cultivar; comercializar madera; pescar; etc.
- La cooperación externa ha capacitado en distintos temas y ha habido mayor presencia de las mismas en las comunidades.

- Factores determinantes: la brutal alteración de los medios de vida, la forma de intervención de la cooperación externa, el tipo de relaciones socioeconómicas dentro de la comunidad previo al HF, la disponibilidad de activos materiales, el nivel académico y el saber hacer.

- Las estrategias de vida de las comunidades eran pesca, caza, agricultura, la crianza de animales de patio y la comercialización de productos agrícolas, maderables y no maderables.

- La dependencia de material vegetativo no es un fenómeno reciente, pero se ha acentuado después del HF.

- La proporción del daño de animales ha aumentado.

- La ayuda asistencialista y prolongada se convierte en un incentivo perverso que inhibe las iniciativas y/o estrategias de los comunitarios para rehacer sus sistemas de vida.

\section{Recomendaciones}

- Los esfuerzos de los comunitarios, la cooperación y el gobierno regional o local e instituciones de desarrollo deberían centrarse en crear condiciones que disminuyan la vulnerabilidad a desastres naturales. Estas iniciativas pueden ser, pero iniciando con la investigación.

- Manejo forestal sustentable apoyando la gestión técnica, la capacidad de negociación y penetración al mercado, el manejo de plantaciones forestales con fines comerciales, haciendo los ajustes necesario en políticas (costos y permisos, por ejemplos).

- Fomento de la producción de frutales con potencial de comercialización o agroindustrial mediante asistencia técnica en el manejo y también mediante el mejoramiento genético. Estos podrían ser el cacao, pejibaye, cítricos (mandarina, naranja, toronja), zapote, entre otros. 
- Evaluación del comportamiento de los parámetros de calidad del agua de quebradas y ríos utilizados para el consumo humano y animal y el uso doméstico.

- Evaluar el potencial farmacéutico o agroindustrial de productos forestales no maderables: aceites (ojón batana, por ejemplo), materia prima para artesanías (tuno, por ejemplo), plantas medicinales (la planta matarronchas importante en tratar problemas en la piel, por ejemplo).

- Investigar sobre los aspectos técnicos que condicionan el rendimiento de los cultivos principales: fertilidad, genética, manejo. Ejemplo: un banco de germoplasma donde se pueda almacenar y reproducir material vegetativo de los tipos y variedades de cultivos existentes.

- Hacer Planes de Desarrollo Comunal con metodologías participativas y por comunidad. Las ideas viables se elaboran a manera de proyectos y deben ser el principal insumo de negociación de las comunidades con las organizaciones de desarrollo presentes.
- Las organizaciones de cooperación deben de planificar considerando el tiempo que las comunitarios requieren para sus actividades productivas y reproductivas y de socialización.

- El apoyo en material vegetativo debe consideran volumen por familia, calidad, cantidad, periodo de siembra, adaptabilidad, asistencia técnica.

- Frente a fenómenos de gran impacto en los medios de vida, no se puede prolongar la ayuda asistencial; es necesario investigar sobre el tiempo necesario en ayuda asistencialista y el cómo apoyar la recuperación. Debe haber sistematización de experiencias a lo interno de las organizaciones y socialización entre ambas.

- Es necesario quizás trabajar una tipología de comunitarios.

- Innovación tecnológica en manejo de ganado (análisis bromatológico, mejoramiento genético, infraestructura, alimentación autóctona).

- Sistematizar todo el conocimiento sobre agricultura tradicional: yuca, arroz, pejibaye, etcétera. 